and were accordingly thought to have M.S., four had results between 45.4 and $47.7 \%$ and were thought to have other neurological disease (O.N.D.), while the last patient gave a $50.8 \%$ result-that is, in the normal range-and her transient disability was thought to be a toxic manifestation of oral contraceptives.

Since the relationship of Devic's disease (neuromyelitis optica) has long been the subject of debate we studied two clear cases of this condition and both gave results in the O.N.D. range.

Your article (like that which appeared in the Lancet $^{3}$ ) dwells on the association between measles and M.S. but passes over recent work in relation to other viruses, in particular the finding of high vaccinia antibody levels in the spinal fluid in M.S.4-6 Nor does it make reference to the extensive researches of Daniel, ${ }^{7}$ who was able to demonstrate a striking association of antibodies against several viruses in M.S. but found no grounds for associating it specifically with measles. ${ }^{8}$-We are, etc.,

A. L. Crombie B. K. SHENTON E. J. FIELD

Royal Victoria Infirmary

Newcastle upon Tyne

1 Field, E. J., Shenton, B. K., and Joyce, G., British Medical fournal, 1974, 1, 412.

2 Jenssen, H. K., et al., Lancet, 1974, $2,1327$.

3 Lancet, 1974, 1, 247 .

4 Kempe, C. H., Pediatric Research, 1972, 6, 384.

5 Kempe, C. H., et al., Archives of Neurology, 1973, 28, 278.

Thompson, J. A., Bray, P. F.. and Glasgow,
L. A., Neurology, 1975, 25, 94.
7 Daniel, P., Nouvelle Presse Medicale, 1972, 1,

T Daniel, P., Nouvelle Presse Medicale, 1972, 1,

Dean, G., in Multiple Sclerosis: Progress in Re-
search, ed. E. J. Field, T. M. Bell, and P. R. search, ed. E. J. Field, T. M. Bell, and P. R Publishing Co., 1972 .

Cerebral Oedema in Diabetic Ketoacidosis

SIR,-Dr. Jennifer S. Moore (30 August, p. 540 ) rightly emphasizes the dangers of rapid administration of hyperosmolar sodium bicarbonate solution to patients with diabetic ketoacidosis. The effect of lowering serum potassium with the induction of cardiac arrhythmias is well described, as is the paradoxical lowering of intracerebral pH. ${ }^{1}$ Dr. Moore does not, however, suggest how rapid intravenous bicarbonate infusion may induce cerebral oedema in this situation. In three of the four cases which she cites death appears to have occurred very soon after hyperosmolar $(8.4 \%)$ intravenous bicarbonate was given, and no comment is made regarding attempted resuscitative treatment administered during the ensuing cardiac arrest. Though the bicarbonate infusion may well have precipitated the fatal arrhythmia, it is not possible to conclude that this therapy produced the cerebral oedema found at necropsy, as cerebral oedema is not in frequently found after cardiac arrest per se. ${ }^{2}$ This is said to result from the excessive anoxia at the time of cardiac arrest, though the literature on the pathophysiology of this phenomenon is extensive and no succinct explanation is available.

In the case described by Dr. J. B McConnell and myself (26 July, p. 208) we were careful to administer $250 \mathrm{mmol}$ sodium bicarbonate $(4.2 \%)$ over three hours, at which time the blood $\mathrm{pH}$ was 6.7 and the actual bicarbonate level was unrecordable. The severe metabolic acidosis was exacerbated by pre-existing renal failure, and in this extreme situation we felt that careful administration of intravenous sodium bicarbonate was justified. It is not clear therefore how hyperosmolar sodium bicarbonate in this situation could produce cerebral oedema, though paradoxical lowering of the $\mathrm{pH}$ of the cerebrospinal fluid (C.S.F.) and brain may have further depressed consciousness. ${ }^{3}$ Most studies sugges that the development of cerebral oedema is closely related to the relative rates of fall of blood and C.S.F. osmolality, ${ }^{45}$ and presumably the rapid addition of a hyperosmola bicarbonate solution during treatment would tend to reverse a shift of fluid from blood to C.S.F. and brain rather than promote it.

Dr. Moore is correct, however, in advocat ing the use of an isotonic solution ( $1.42 \%)$ of sodium bicarbonate for patients who have severe plasma hyperosmolality, where this is indicated by the degree of acidosis.-I am etc.,

Ninewells Hospital,

B. M. FRIER

Dunde

Posner, J. B., Swanson, A. G., and Plum, F. Archives of Neurology, 1965, 12, 479.

2 Stephenson, H. E., Cardiac Arrest and Resuscitation, 4th edn. C. V. Mosby Coy., Ch. 56, 695 Posner, J. B., and Plum, F., N of Medicine, 1967, 277, 605 .

Fulop, M., Lancet, 1973, 2, 635.

Arieff, A. 1., and Kleeman, C. R.

Clinical Investigation, 1973, 52, 571 .

\section{Certification of Death}

SIR,-Your leading article on the Government's proposed implementation of the Brodrick report (30 August, p. 506) oppose such legislation on the ground that accurate mortality statistics are necessary for the identification of environmental hazards. As a district community physician and a crematorium referee, I would be the last to disagree with such a contention except that I cannot see that, for all the wad of form to be completed, the cause of death is one iota more accurate under this system than under the one to be adopted.

The "ordinary medical attendant" or some acceptable substitute completes form $\mathrm{B}$. $\mathrm{He}$ suggests a cause of death and, unless a postmortem is carried out, nobody can gainsay it The second doctor, in the absence of necropsy, simply rubber-stamps the opinion of his colleague-what other option has he in most cases? The referee can only look through the papers to see that the law has been complied with (in spirit only on occasion-the stipulation of "ordinary medical attendant" becomes somewhat meaningless in these days of large partnerships) and that the cause of death is reasonably consonant with the time scale over which it occurred and adequate in indicating true causes rather than effects. It is not possible for the referee to debate the cause of every death in detail and, assuming there is no suspicion about the death, many an inadequate cause must pass unquestioned. What a chore it would be to correct every epidemiological howler made! Could any mortal stand the consequent opprobrium?

Thus I confess that, however much it may brand me a blackleg, I must support the proposed legislation and suffer the modest loss of emoluments with fortitude, seeing in your own leading article a regrettable lack of realism.-I am, etc.,

Bromsgrove, Worcs

\section{Services Available for Total Joint Replacement}

SIR,-Dr. J. R. W. Morris (2nd August, p. 290) and Dr. B. T. Williams (30 August, p. 541) have both overlooked revision operations as an additional demand on bed occupancy arising out of total hip replacement operations. Revisions for whatever reason are fortunately uncommon, but treatment of, for example, a late deep infection may require a longer inpatient stay than the original replacement, and subsequent admissions may be necessary.

Dr. Morris describes the total joint replacement services as being saturated, and few surgeons would disagree. While it is important to present a case for an increase in the number of orthopaedic beds to allow more joint replacement operations to be performed, such arguments are almost certain to fall on deaf ears at the Department of Health and Social Security in the current economic climate. Indeed, the report of a British Orthopaedic Association subcommittee $^{\mathrm{l}}$ indicated the inferior provisions considered adequate by the D.H.S.S. for orthopaedic and trauma surgery in 1973.

Nevertheless, the profession should not raise the clinical criteria for replacement or any other operations in order to keep the waiting lists stable. To do so would be to break faith with its patients and to adopt false standards. The present inadequacies, which are bound to increase, must be kept firmly in front of the D.H.S.S. and not disguised in any way. Though long waiting list: are a great burden to the surgeon, who has to answer the plethora of letters from patients and general practitioners, they provide the only reasonable indication of the adequacy or otherwise of the orthopaedic service. Alas, as we know, even this can be disguised. Dr. Morris quotes from D.H.S.S. statistics the median waiting time for total hip replacement in 1973 as 16 weeks. This figure will, however, include partial replacements performed urgently for femoral neck fractures. Dr. Williams has analysed the waiting time for total hip replacement in the Trent region for $1973^{2}$ and reported his results in a different manner. He found that $25 \%$ had waited for more than one year and $5 \%$ for more than two years. It is statistics of this latter type that reflect the true situation as experienced by patient and surgeon alike and indicate, given standard selection criteria, the adequacy or inadequacy of the service.-I am, etc.,

Leicester

R. T. AUSTIN

Casualty Departments, Accident Commission Report of the British Orthopaedic Association, 2 Williams, B. T., Total Hip-joint Replacement in the Trent Region, unpublished.

\title{
Estimation of Glomerular Filtration Rate
}

SIR,-A single-shot isotope method for the determination of the glomerular filtration rate (G.F.R.) has obvious attractions to the clinician seeking information on overall renal function as an initial screening or follow-up procedure. Hard-pressed nursing staff share this enthusiasm as urine collections are avoided. The ${ }^{51} \mathrm{Cr}-\mathrm{EDTA}$ clearancel correlates well with 24-hour endogenous creatinine clearance, and the single-slope method of anaiysis described by Chantler et al.,2 using three or four blood samples, is now widely 
used. The recent modification of this method by obtaining a single blood sample three to five hours after injection (Mr. M. Fisher and Dr. N. Veall, 7 June, p. 542) simplifies the technique further. We would like to comment on the clinical value of this modification, using data from approximately 300 patients in which the G.F.R. was measured by a twocomponent analysis ${ }^{3}$ of the ${ }^{51} \mathrm{Cr}$-EDTA clearance curve, using seven blood samples taken within five hours of injection.

We have found a similar trend to that obtained by Mr. Fisher and Dr. Veall when two, three, four, and five hour regressions are used, confirming the value of the method when the G.F.R. is normal or moderately reduced ( $>30 \mathrm{ml} / \mathrm{min}$ ). There is reduction in accuracy when the G.F.R. falls below this level, but a further blood sample taken after another two or three hours enables the single-slope method of analysis to be used, with considerable improvement in accuracy.

The optimum timing of a single blood sample for greatest accuracy appears to depend on the level of the G.F.R., with a twoor three-hour sample appropriate for estimation of high values and a four-or five-hour sample more suitable for low values. The suggestion that correction for body surface area may improve accuracy is not borne out by our data, and body weight correction is also of little value, implying that individual differences in ${ }^{51} \mathrm{Cr}$-EDTA distribution are not significantly influenced by these parameters.

The simplicity of a single blood sample outweighs the modest improvement in accuracy obtained with multiple samples and we welcome this modification. For serial follow-up of individual renal problems reproducibility is more important than absolute accuracy, and we find that the single-sample technique proves adequate for this purpose. -We are, etc.,

W. D. MORGAN

J. L. BIRKS
A. SIVYER
R. R. GHOSE

Medica! Physics Department, Medical Department,

Singletor, Hospital,
Sketty. Swansea

1 Garnett, E. S., Parsons, V., and Veall, N., Lancet, 1967, 1, 818.

2 Chantler, C., Clinical Science, 1969, 37, 169.

Physiology, 1955, 181, 330 .

\section{Adjustment to Low-dose Heparin} to Prevent Thrombosis

SIR,-Your leading article on "Low-dose Heparin and the Prevention of Venous Thromboembolic Disease" (23 August, p. 47) is, I think, a very fair summary of current opinion. However, there is one point I tried to make at the King's College Hospital meeting that I believe will make this regimen even more effective.

It has been known for a long time that the results of various clotting tests involving the addition of heparin are short relative to controls in many of these patients. ${ }^{1}$ This indicates that the patients have an excess of heparin neutralizing activity (H.N.A.). There is evidence that this H.N.A. in the plasma may represent platelet factor 4 liberated from "activated" platelets. ${ }^{2}$ However, irrespective of the origin or the theoretical significance of this H.N.A., wide differences are found clinically; particularly high activity occurs in acute deep vein thrombosis ${ }^{3}$ and in acute myocardial infarction ${ }^{4}$ and this must influence the effect of the heparin therapy.

In general I am sympathetic to the concept of giving a single standard dose per ampoule twice or thrice daily. Nevertheless, it seems only rational to make some allowance for the amount of heparin which will be immediately neutralized. Monitoring the heparin level (for example, by the method of Denson and Brennar ${ }^{5}$ ) is not easy in a busy routine laboratory and is probably not justified except in special cases, but a single pretreatment assay of H.N.A. is easy and quick. It has not yet been shown whether adjusting the dose to the patient's weight and the current level of H.N.A. is in fact beneficial, but logically such adjustment should give better protection and decrease the risk of haemorrhage. I am, and I hope others are, working on this problem.-I am, etc.,

Portsmouth and South East Hampshire

J. R. O'BRIEN

District Pathology Service, Portsmouth, Hants

1 O'Brien J. R., Thrombosis et Diathesis Haem-

2 O'Brien, J. R., et al., Lancet, 1974, 2, 656.

3 Green, P. J., Lancet, 1975, 1, 799.

O'Br:en, J. R., et a'., Fournal of Clinical Patrology. In press.

et Di, K. W. E., and Brennar, J., Thrombosis et Diathesis Haemorrhagica, 1973, 30, 471.

\section{Urinary NAG Activity in Renal Disease}

SIR,-The paper by Mr. J. M. Wellwood and others (16 August, p. 408) on urinary $\mathrm{N}$ acetyl- $\beta$-D-glucosaminidase (NAG) raises several points which are worthy of comment. In expressing enzyme activity, " $\mathrm{nmol} \mathrm{h}^{-1}$ " would surely be better converted to $U$ or $\mathrm{mL}^{-}$as defined in the Enzyme Commission recommendations, ${ }^{1}$ which would avoid the possible confusion between hours of incubation time and hours of urine output.

The authors state that there is no age dependence of urinary NAG excretion, but more details would have helped, since in fig. 1 there is an increase in mean value with age which seems to be quite marked for males when the first decade is excluded. The apparent fall in mean excretion for females between the fourth and fifth decades is also interesting since this would coincide with the time of the menopause; is this of any significance?

The authors express urinary enzyme excretion in relation to urinary creatinine output in order to avoid variations in daily urine volume and to avoid timed collections of urine. They then continue by noting increased NAG excretion in patients with renal disease and in particular those with increased serum creatinine. But is it not possible that the apparent increase in NAG excretion results from a reduced creatinine output in the urine, which may be present in renal disease with elevated serum creatinine, and not from a true increase in NAG excretion rate? Unfortunately details of the urinary creatinine output are not given in the paper. The NAG values given in the paper can be accpted as being due to a true increase in NAG excretion rate only if it has been shown that there is normally a significant direct correlation between NAG excretion rate and urinary creatinine output, so that a fall in urinary creatinine is associated with a fall in NAG excretion. Then in renal disease an increase in NAG expressed per mg creatinine will truly be due to an increased excretion rate of the enzyme.

The problem of timed collections has been overcome for urinary $\gamma$-glutamyl transferase by using a random sample where the time interval from the previous voiding is known. An excretion rate can thus be calculated and this has produced no problems due to excessive changes in urine volume or to variation in excretion rate throughout the day.-I am, etc.,

Biochemistry Department,

P. R. BECK

Royal Infirmary,

Glasgow 1 International Union of Biochemistry, Enzyme
Nomenclature. Amsterdam, Elsevier, 1965.
2 Beck, P. R., M.Sc. Thesis, University of Birming-
ham, 1974.

\section{Myocardial Scanning}

SIR,-We were interested in the paper by Dr. J. T. Innes and others (30 August, $517)$ on myocardial scanning using $99 \mathrm{mTc}$ stannous pyrophosphate, having ourselves used a similar technique in 52 patients with suspected myocardial infarction. A rectilinear scanner rather than a gamma camera was used, thus making it within the resources of most district general hospitals. This was mounted on a simple mobile frame so that scanning could be performed at the bedside with minimal disturbance to the patient. A dose of $8 \mathrm{mCi}$ of the isotope was found sufficient.

Positive scans were found from 17 hours to 18 days after the onset of symptoms. We found the anterior scan to be the most useful view, an abnormal result being indicated by asymmetry about the sternum. When infarction was "definite" from the story, electrocardiogram, and enzyme changes the scan was positive in all of 15 patients, when "likely" in 12 of 16 , and when "doubtful" in nine of 21 .

Heart scanning using 99m Tc-stannous pyrophosphate seems useful in the assessment of suspected myocardial infarctions. These preliminary studies suggest that it is reliable, safe, sensitive, and of particular value when previous damage makes electrocardiographic interpretation difficult and when raised enzyme levels cannot be attributed with confidence to the heart.-We are, etc.,

\section{E. J. WAKLEY}

J. RUSSELl REES

E. RHYS DAviES

G. E. STADDON

Bristol General Hospital,

Bristol

\section{Malaria in Scotland}

SIR,-During 1970-4 104 cases of malaria were reported from laboratories in Scotland. ${ }^{1}$ Twenty-six of these admitted to this department fell into three categories.

All 13 Asians had been visiting Asia after living in the United Kingdom for several years. None had taken malaria prophylaxis, though before starting their trip most had acquired smallpox vaccination, which could have provided an opportunity for advising on antimalarials.

The two West Africans in the series had both discontinued long-term pyrimethamine on leaving Africa and subsequently developed falciparum infection. With increasing use of 